\title{
The Perceived Destination Identity of Stakeholders: a Case of Chang Island
}

\author{
Panita Preechawong, Ousanee Sawagvudcharee \\ Graduate School, Shinawatra University, Thailand \\ panikacurtain@hotmail.com, Ousanee.s@siu.ac.th
}

\begin{abstract}
The tourism industry in Thailand is a significant economic activity due to the large and increasing number of tourists, facilities, accommodation and revenue. It is likely to increase its contribution to the GDP from its already significant role of more than 10\%. Additionally, the tourism industry career opportunities and helps spread prosperity throughout the kingdom. Chang Island is no exception. Tourism on Chang Island is arguably the most important revenue-generating sector because of the income and job creation. Much of the competition in tourism focuses on tourists' ability to recognize and remember a particular destination as being unique. Because of this, the development and use of a strong destination identity is critical when making strategic marketing plans. Many tourists will select their holiday destination from their memory of, or recognition of a destination identity. That is why the message behind a destination identity should be a topic to highlight. The aim of this study is to gain insight into the real-life perception of Chang Island's destination identity by its sender stakeholders. This will help the researcher identify key issues that allow for the development of a suitable guideline for review and possible revision of the island's destination identity. A qualitative analysis of data collected in this study provides a grounded theory, to support the perception of the sender side of Chang Island's stakeholders.
\end{abstract}

Keywords: Destination identity, tourist's recognition, the perceived of destination

\section{Introduction}

People value travel and it is a fact that many people undertake regular holiday travels to break up their routine. When they travel, most visit new places and make new friends, which help them increase their sense of self-worth (Buckley, 2010). Some define their perfect holiday as one where they: increase their personal knowledge, gain new experiences and widen their personal horizon or prospective. In addition, travel holidays are opportunities to create memories that last a lifetime, ultimately making them happier people. Because so many do recognize the value of travel and actually go on holidays, the global tourist industry has grown and developed to the point where it has become a significant business sector that has the potential to produce revenue in virtually every country on the planet. Moreover, it can also play a significant role in each country's economic development. Because of the benefits tourism brings in terms of direct revenue and increased jobs, people within the industry, as well as government entities, focus resources on the issues surrounding tourism development; which is why the concept and perception of 'destination identity' is a legitimate topic for research and consideration. Tourists' perception of a location's or attraction's destination identity has become more important for stakeholders of these tourist destinations and because the tourism industry is increasingly competitive, direct competition between and among the attraction/destination stakeholders is increasingly aggressive. Koh Chang Marine National Park (KCMNP) is no exception.

Much of the competition in tourism focuses on tourists' recognition: where they can easily recognize and remember a place or attraction uniquely. It is important to determine the destination identity when developing strategic marketing plans for a particular destination because of the potential to increase positive tourist recognition, loyalty to it and ultimately, increased satisfaction. Furthermore, astute stakeholders realize that a tourist destination should possess a unique image and that more successful attractions usually have a stronger image than their competition. Generally, most tourists will select their preferred destination based on how well they personally relate to the destination identity. The source of information the tourist uses to make their decision can come from a stakeholder's role in the development of destination identity such as, existing social, cultural, historical and geographic values, as well as, other unique points that 
differentiate their destination from others attempting to reach the same market and pool of potential tourists. Stakeholders in destination identity studies can be segmented into two sides: (1) senders' side and (2) receivers' side. For the purposes of this study, the researcher will limit activities and analysis to the sender side stakeholder community in order to get a clear view of collective viewpoints of stakeholders who, by virtue of their position, share similar interests with respect to the destination identity. Additionally, it should be possible to view and analyze their individual and collective activities. The stakeholders in this study consist of: authorities charged with the care of the National Park, tour operators, marketing organizations, representatives from Chang Island hotels and resorts, local citizens, the division within Tourism Authority of Thailand (TAT) that has responsibility for KCMNP, and lastly, the officers from local government sectors. This collective plays the central role in the development and overall success of KCMNP's tourism.

The goal of this project is to provide a good set of guidelines that sender-side stakeholders can use in the development of a world-class destination identity; the result of which will help improve KCMNP's revenues on a long-term sustainable basis, as well as, ensure the local community gets the benefits associated with a successful tourist destination in the form of more jobs, better jobs, improved services and increased quality of life. For decades, stakeholders in KCMNP involved in tourism development have faced challenges creating a powerful tourism destination identity as well as understanding visitors' and local residents' attitudes and perceptions. Moreover, these perceptions can have a significant influence in the destination decision making process of potential tourists. The tourism industry in Thailand is one of the biggest economic drivers in the economy. The country in fact, earns a significant amount of revenue from both domestic and international tourists. Because the number of tourists has a direct effect on related industries, such as hospitality, tourism has a significant effect on the Gross Domestic Production (GDP). In addition, the tourism industry provides career opportunities and helps spread prosperity throughout the kingdom in the form of improved infrastructure, better transportation as well as increased trade and investment. A measure of the impact tourism has on the Thai economy is shown in the 2015 GDP numbers; where even though the country faced an economic crisis, tourism still contributed 14\% to the GDP (National Economic and Social Development, 2015). On Chang Island, tourism and hospitality industries are the most significant source of jobs, and play a leading economic role in the local economy. Development though, must be balanced against the need for environmental protection, which helps ensure the sustainability of the island as a tourist destination.

The tourism industry in KCMP requires improvement in order to provide a better tourism destination identity. In particular, this refers to Chang Island. An improved destination identity can help the island effectively share its message to potential tourists, ultimately stabilizing and growing the number of visitors every year. It is necessary though, that this activity be actively supported by the stakeholder community. Koh Chang Marine National Park (KCMP) is one of 127 national parks in Thailand of which, 22 are Marine National parks. In the past, KCMP was a very popular destination and Chang Island, as the largest most developed island in the park, benefitted the most. However, in recent years, tourist arrivals to Chang Island have significantly decreased from its peak in 2010. This study aims to gain insight into the situation behind the lackluster arrivals numbers for KCMNP and to explore the perception of the sender side of Chang Island's stakeholders. This should help the researcher identify key issues that will allow facilitate development of a suitable guideline to generate a strong, viable destination identity. Analysis of resources, competencies and capabilities of the locale is the basis from which the destination brand identity can be developed.

\section{Literature Review}

Destination identity: Bregoli (2012) found that destination identity is based on the collective views of local communities and business operators and a well-designed destination identity seems to create a sense of belonging to the people who live and work there. An appropriate process for creating destination identity is important in order to attract tourists domestically as well as internationally. Some researchers see that destination identity is important in the overall success of a tourist destination. Cai (2002) \& Mak (2011) studied the creation of destination identity to determine its importance as the components can emerge from involvement and participation in the branding process. Saraniemi (2011) said that the destination identity is often captured from the user's point of view, namely, the tourists themselves. Therefore, it can 
be concluded that destination identity comes from the perception of several supply-side stakeholders combined with the point of view of tourists regarding the destination.

Destination: Pike (2004) said that destination is a place that attracts travelers for a momentary stay, to participate in tourism related to activities or perhaps, non-activities. Destination can be a more perceptual concept, which is a subjective viewpoint by consumers. Buhalis (1999) stated that a destination can be gathered together as combination or a brand of all products, services and locally provided experiences. This can be developed within the Six A's framework for tourism destination analysis: attraction, accessibility, amenities, available, activities, and ancillary. Framke (2002) defined destinations as a part of the tourism system. In this way, at any particular destination there is unique combination of the constituent elements that is interdependent to produce satisfaction for tourists. It can be concluded that destination is a place that travelers visit for a momentary stay. It involves a combination of activities or non-activities and includes tourism products that support services and tourist attractions. A destination can be gathered as combination of services and locally provided experiences. It is possible to assess the impact of tourism regionally, for example, Chang Island. Lastly, it can be developed in the six A's framework for tourism destinations.

Identity: Rummens (1993), Beller \& Leerssen (2001), Weinreich \& Saunderson (2003), and Oyseman (2007) found that identity is the concept of quality, belief, and values that make a person or group different from others. It also refers to the unique sense of self and mutual feeling in awareness in each individual and it also means social relation and social group to define who "I" am. Identity is like two sides of the same coin: one side is feeling unique while the other is people feeling the same. Therefore, identity is one's self-image, or desired image, due to inputs from other outside sources. In addition, identity is given meaning via symbolic systems regarding identity position. This is, at its core, the individual characteristic of a brand image. In marketing, Aaker (1996) explains that the structure of brand image is composed of core identity and extended identity (see Figure 2). The core identity is the brand essence of the product. It remains firmly with the product. It is like the heart that reflects the soul of the brand, based on belief and values that will drive the brand to its maximum potential.

The stakeholder: Sheehan \& Ritchie (2005) defined stakeholders as the group or individual who can affect, or is affected by the achievement of a corporation's purpose. Stakeholders are not only responsible for promoting the destination, but also to guide and encourage the public and private sector investment in order to develop the products. Starik (1994) stated there may be numerous levels of specificity within the definition of stakeholders, and indeed, there is some flexibility in the definition depending on the circumstances, viewpoint and specific situation. Destination Management Organizations (DMOs) recognize stakeholders as being important, " [stakeholders]depend on potential tourists and their perception of the destination". They also supply and facilitate funding, provide the tourism promotion and products, participate, as well as, support tourism programs and policy. Pike (2005) says that DMOs depend on potential tourists and their perception on the destination. The local tourism community is responsible for delivering brand promises and they have to capture and share, with the visitor, the feeling or sense of the identity towards the brand associated with a destination. Konecnik \& Go (2008) emphasize that destination identity plays an important role as brand identity, which assist tourism authorities in creating a strong brand. This helps provide a vision of how the brand should be perceived. For Chang Island, there are both internal external stakeholders. Internal stakeholders refers to people who live and work at Chang Island. These people are in both the public and private sectors, e.g. authorities of Chang Island, tour operators, marketing organizations, entrepreneurs, citizens, the Tourism Authority of Thailand (TAT) who are responsible for TAT activities for Chang Island, and the officers from local government sectors. The term 'external stakeholder' refers to tourists who are visiting Chang Island.

Image: Rope \& Mether (2001) said that image is combination of a person's experiences, attitudes, beliefs, feelings and knowledge towards something. In general, when considering the concept of image of something or someone, it can be said to be a perception in a person's mind. Buhalis (2000) said that before travelling, people go to a destination by developing the image and a set of expectations based 
on previous experience, word of mouth, press reports, advertisement and common beliefs. In a similar way, Morrison and Anderson (2002) said that the definitions of destination image is the sum of ideas, beliefs and impressions that a person has of a destination. Bonn et al. (2005) explain that destination image is influenced by the environmental attributes and atmospheric attributes: landscapes, historical attractions, infrastructure, accommodation, facilities, and service attributes. Tourism managers can use these characteristics to manage the formation of a destination image by potential tourists. In marketing, Aaker (2002) said brands have dimension and structure and can be divided into four different perspectives: the brand as a product, the brand as an organization, the brand as a person, and the brand as a symbol. The objective of these different perspectives is to help when considering the different elements and patterns of the brand, which help in differentiating, clarifying, and enriching an identity. To summarize: destination image is previous experience in mind of a person. That means products, services, and organizations which consist of beliefs, feelings, and knowledge of the destination influence a tourist's decision to choose to travel to Chang Island. A clear, powerful image of Chang Island in tourists' minds will more likely occur when effective consistent communication occurs across a long period whereupon, understanding and feeling of the essence of Chang Island embeds in the mind of the potential tourist.

Brand personality: Murase \& Bojanic (2004) defined brand personality as a set of human characteristics. Tybout \& Stephen (2005) said there is a relationship between consumers and the brand if the brand personality characteristic matches consumer demand. If the brand can express consumers' social status, they will feel more familiar and more content with the brand. Harris, \& Chernatony (2001) explain that brand personality can help strengthen the synergy between its market positioning and throughout the branding process as well. Aaker (1997) states that the personality set is based on five dimensions: Sincerity, Excitement, Competence, Sophistication, and Ruggedness. It can be concluded that brand personality creates the difference of a particular brand product from its competitors. The study of inbound tourists attitude toward the personality of Chang Island can help us understand the status of Chang Island in tourists' perception. This data can be used to form a guideline for the creation of an improved destination identity for Chang Island.

Perceptions: American Heritage (2013), Armstrong \& Kotler (2007) and Schiffman \& Kanuk (2000) define 'to perceive' as to see, to hear, to feel something, to have an understanding of something and to become aware of something directly through any of the senses. The perception is the process through which an individual selects, organizes and interprets information inputs to create a meaningful picture. Flanagan \& Lederman (2001) argues that the perception means acceptance, correction, ownership, and understanding with sense. Similarly, Kotler (2000) said that selective perception refers to the way which all consumers perceive the information they have given their attention to. There is a tendency to manipulate and interpret information into something with personal meaning. Therefore, perception is the process of a person's response combined with experience. The perception is an important process to consider when creating marketing communication. 


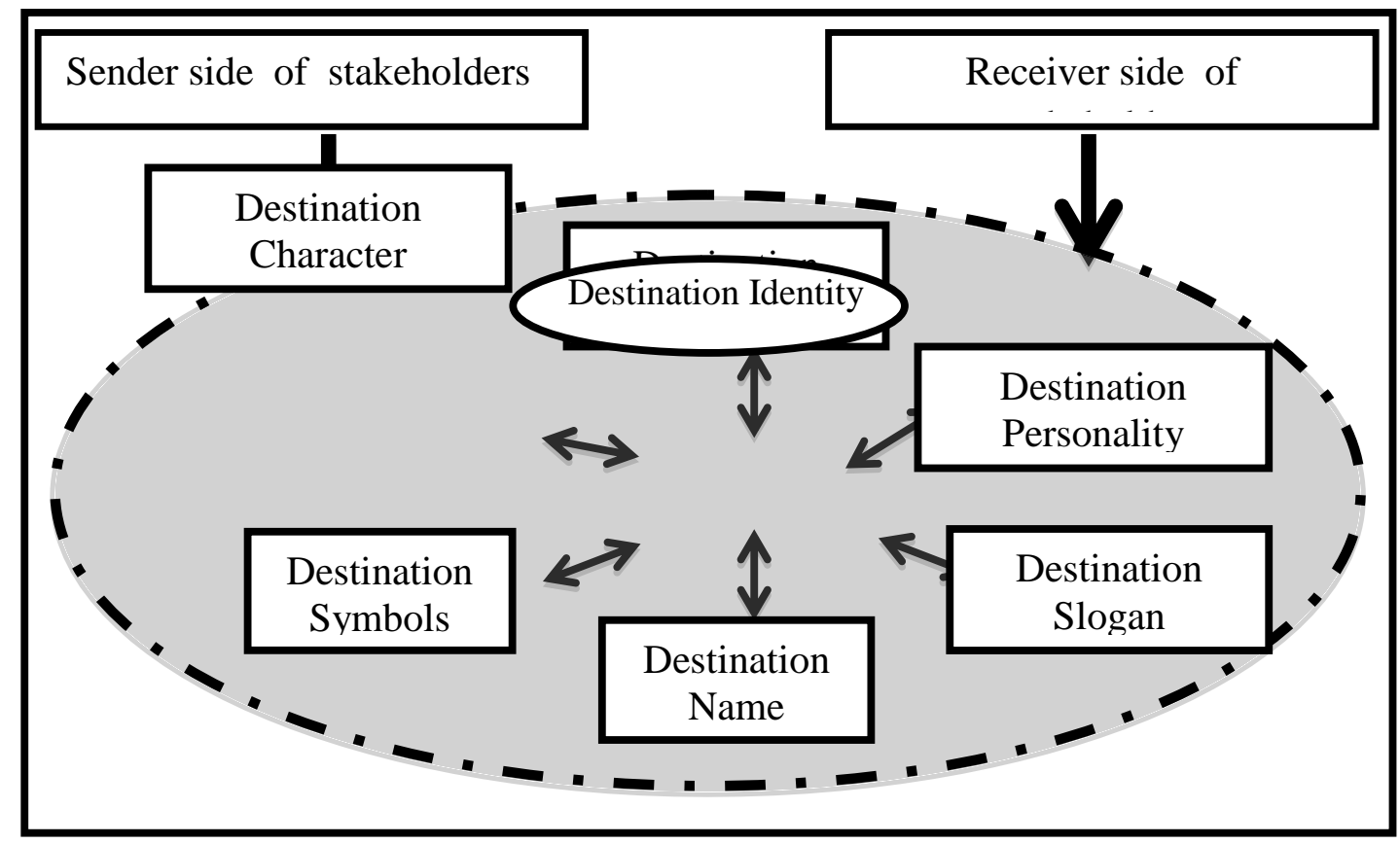

Source: Adapted from Aaker, (1997)

Destination Identity Model: From the destination identity model, the component of destination identity, according to Aaker (1997) involves six components. These components are

- Destination culture: It is the aspects of the people (spirit, traditions, event, etc.), and the aspects of country (historical sites, monuments, archaeological sites, etc.). It can be considered an essence of the destination.

- Destination character: relates to its internal constitution, which is perceived in terms of integrity, trustworthiness, and honesty (Upshaw, 1995). This is the promise of the brand to deliver the experience associated with its distinctive value proposition.

- Destination personality, as defined by Aaker, $(1996,1997)$, is the set of human characteristics that are associated with the destination. It includes several characteristics, such as sincerity, excitement, competence. Moreover, it also embodies gender, age, socioeconomic class, as well as human personality traits such as warmth and sentimentality.

- Destination name is often the original name of the destination, whether in dialect or in English language: this choice is more important, because it is strongly related to communication strategy on tourist targets. Destination name should have many strength and unique associations. It should be distinctive, pronounceable and recallable (Keller, 2003b).

- Destination logo and symbol are fundamental elements used to define a destination. A beautiful view, a famous monument or an unique tradition are examples of symbols that in destination case could be the main logos to communicate a clear and distinctive value proposition compared to another competitive places.

- Destination slogan represents a promise that a business player defines to the tourist targets. It's based on the main functional, emotive or experiential attributes of the destination, related to the benefits and value provided by the place offering.

The six elements are essential in generating destination identity to represent the identity of the destination. It is also important to analyze its cohesiveness which depends on the consistency of these elements ( Keller, 2003a). The 6 element model is a known and tested method for generating a unique and powerful 
tourism destination identity. Good destination identities help tourists recognize and remember the differences between competing destinations when making travel decisions. Therefore, creating a unique, powerful and appropriate Chang Island destination identity should be a significant way to encourage potential visitors to choose a Chang Island holiday.

Koh Chang Marine National Park (KCMNP): Koh Chang Marine National Park (KCMP) is a 42 island archipelago in the Gulf of Thailand. It is located in Trat Province in the Eastern region of Thailand close to the Cambodian border, nearly 8 kilometers from shore. Within KCMP, the most significant tourist destination is called Chang Island or Koh Chang. The Island, the second largest island of Thailand after Phuket Island was declared a district of Trat province on $24^{\text {th }}$ August 2007. Because of its size and prominence as the second largest island in the kingdom, there are many visitors. In the past, the island while technically uninhabited was used as a port to escape the monsoon, as well as, provision resources. Later on, the Island was developed as a tourist destination and was designated a national park on 31st December 1982 to become the $45^{\text {th }}$ national park in Thailand. This study will limit its focus to Chang Island specifically.

\section{Methodology}

This chapter details the research methodology for this study. The study uses the case study approach as well as a qualitative methodology. This study focuses on the question "How does the sender side of Chang Island" stakeholders perceive its destination?" The objective is to expose the perception of stakeholders on Chang Island by using the interview questions as a base for a research conceptual framework. The question base for the destination identity model relies on the 'six dimensions' concept. These dimensions are destination: culture, character, personality, name, symbol and slogan. The researcher collected data between 15 January 2016 - 15 April 2016 and limited responses to focus on this specific study exclusively. Consequently, the researcher decided to interview fifty people from the sender side of Chang Island's stakeholders. It consists of Koh Change Marine National Park (KCMNP) (3 interviewees), Tour operators (4), Marketing organizations (2), Entrepreneurs (hotel/ resort/ restaurants on Chang Island) (15), Chang Island general citizens (20), The KCMNP's Tourism Authority of Thailand (1) and The Chang Island Sub district Administrative Organization (5).

The process of this research is qualitative research by using an in-depth interview with semi-structured question set and analysis by using content analysis. Moreover, to gain an insight into the situation, the researcher used face-to-face in-depth interviews with the sender side of Chang Island stakeholder. This is because the study needed to gather unique perspectives from each of them. Before starting the interview, the researcher asked for permission to record the session. Following the interview, the researcher transcribed word for word from recording, then aggregated the data to ensure confidentiality of the interviewees. Those data were used for this research only and no individual interview records have been archived for outside access nor are they available by request. This study uses qualitative analysis of information from data collected during 50 separate interviews. The analysis was done qualitatively and analysis performed by grouping: giving frequency and then percentage.

\section{Results}

Destination identity consists of destination culture, destination character, destination personality, destination name, and destination symbol. Results of the study are as follows:

What are the cultures of Chang Island? When interviewee were asked about destination culture of Chang Island. They looked at three dimensions: food culture, old traditions, and historical events.

Food culture: the most common answer was seafood (70\%). The second was shrimp paste and the foods made from shrimp paste (68\%). And the third are local foods (56\%) . Due to the traditional lifestyles farming and fishing, which main products for cooking come from the sea, most notably: fish (both large deep water and small fish), shrimp, crab and shrimp paste. Fresh seafood is often a major influencer when certain tourists select a holiday destination). In addition, expanded career opportunities in the tourism 
industry are available - of particular note: cooking school programs. This is a proven attraction for tourists in other destinations and the fact that Chang Island has so much seafood opens the opportunity to create a unique identity in this area.

Traditions: most interviewees responded to the question of traditions was 'Loykratong' (50\%).

Due to the relatively short history of Chang Island, no real island-specific traditions have yet evolved.

Historical event: the majority of interviwees response was the Thai Navy Battle (100\%). Chang Island was the site of several notable events such as Thai Navy Battle and the visit of King Rama V. "Thai Navy Battle" is important in history of-Chang Island, for it was the site of a significant battle between the Royal Thai Navy and French Navy during World War II. A monument dedicated to the event does exist on Chang Island. These historical events provide a good basis for festivals that can attract tourists thereby increasing the value of Chang Island as a tourism destination.

What are the characteristics of Chang Island? This question aims to compare Chang Island attributes to human characteristics. This question relates to the characteristics within Chang Island that the stakeholders' perceive in terms of honesty, reliability, trustworthiness - all of which are human characteristics. The most common answers were reliability $(80 \%)$. The most noted natural features of Chang Island are embodied in the wonderful natural environment, both on the ground and under the sea. Typical within the responses were: beautiful, quiet place, variety of natural features: waterfalls, white sand beaches, old growth forests, wild animals and dive sites. In addition, there are several types of natural and wild herbs growing on the island. Furthermore, there is a comfort and trust that Chang Island is a safe and secure Tourism destination. The people are kind, sincere and friendly. Those characteristics of Chang Island are important in terms of competition with other destinations.

What is the personality of Chang Island? This question attempts to understand perceptions of the island in terms of a 'personality'; so sincerity, excitement, competence, sophistication and ruggedness personalities are the typical human-like attributes used. Also, human personality traits such as warmth and sentimentality are also used in this context. Most interviewees thought Sophistication personality (56\%) was the dominating trait. The destination personality is key to creating destination differential for the targeted base of tourists. The destination personality displays specific characteristic images, which triggers the imagination in a tourist's mind in a differentiable manner compared to other tourist locations. The imagination-based imagery, if well designed in the destination personality increases competitiveness and should yield improved customer numbers.

What is original name of Chang Island? Uniformity regarding the name(s) of the destination is important for creating a good communication strategy in tourism development. The destination name should be distinctive, pronounceable and easily recalled by the tourist. Most interviewees answered "Chang Island" in response to the question (94\%). The name Chang Island is easy to pronounce and recognize which helps tourists retain the information. When tourists recall the name of Chang Island, it triggers specific images in tourists mind. Furthermore, the name is easy to use when describing Chang Island to others by word of mouth.

Does Chang Island have a slogan? Slogans can tell customers what the product is like. Thus a slogan for Chang Island should convey an image in the mind of the tourist that quickly captures the 'Chang island experience'. It's based on the main functional, emotive and experiential attributes of the destination. Most interviewees responded that they did Not know of any slogan for Chang Island (94\%). Thus, Chang Island should probably create one in order to reinforce the destination image with tourists. This will help tourists remember, understand, and confirm the intent of senders. Any slogan for Chang Island must be easy to remember and convey, very quickly, the destination identity.

What should be an ideal logo for Chang Island? This question aims to raise awareness of interviewees about the importance of a logo for Chang Island. A well designed logo will help tourists remember the destination identity and recall its name. A logo is a fundamental element in defining a destination. At Chang 
Island, a beautiful view, a famous monument and unique traditions are examples of symbols that could be used in the main visual element of a logo to communicate a clear and distinctive value proposition compared to another competitive places. deruovaf seeweivretni tsom The island map with an elephant picture.

\section{Conclusion and Implications}

This study aims to gain insight into the situation behind the lackluster arrivals numbers for KCMNP and to explore the perception of the sender side of Chang Island's stakeholders. This should help the researcher identify key issues that will facilitate development of a suitable guideline to generate a strong, viable destination identity. Analysis of resources, competencies and capabilities of the locale is the basis from which the destination brand identity can be developed. The literature review on the topic of destination identity comes from the perception of several stakeholders about the potential of destination tourism combined with the understood point of view of tourists. A destination can be described as a combination of services and locally provided experiences. In addition, the core identity is the brand essence of the product. The term, 'internal stakeholders', refers to people who live and work at Chang Island. These people are in both the public and private sectors, e.g. authorities of Chang Island, tour operators, marketing organizations, entrepreneurs, citizens, the tourism authority of Thailand responsible for Chang Island, and the officers from local government sectors.

Research methodology for this study explains how qualitative research was conducted: a case study approach was used as well as a qualitative method applied. For the qualitative perspective interviews, the study was conducted with fifty subjects selected from a 'pool' of sender side Chang Island' stakeholders. The subjects were interviewed in depth using a semi-structured question format. This study uses qualitative analysis of information collected from the completed interviews. Then analysis completed by grouping: giving frequency and percentage using content analysis to identify data from the interview. The results confirm the previous argument that the culture of Chang Island in terms of food culture is seafood, old tradition is Loykratong, and historical event is Thai Navy Battle. The chief characteristic of Chang Island is reliability. In addition The personality of Chang Island is sophistication. The original name of Chang Island is Chang Island and it does not have a slogan. Recommendations for a future study destination identity of KCMNP should capture and analyze inputs from both senders and receivers side as this study was performed on sender-side stakeholders only. Further study, using both sides should illustrate alignment and misalignment between what the sender-side stakeholders believe is ideal and what potential and experienced visitors think and experience.

\section{References}

Aaker, D. A. (1996). Crandon e administrando marcas de sucesso, Fu- tura, São Paulo.

Aaker, J. L. (1997). Dimensions of Brand Personality. Journal of Marketing Research, 34, 347-56.

Aaker, D. (2002). Building strong brands. London: Free Press.

Armstrong, G. \& Kotler, P. (2007). Marketing an introduction (8 ${ }^{\text {th }}$ Ed.). Upper Saddle River, N.J.: Pearson Prentice Hall.

The American Heritage $®$ (2013). Dictionary of the English Language, 5th edition Copyright $\quad$ C $\quad 2013$ by Houghton Mifflin Harcourt Publishing Company. Published by Houghton Mifflin Harcourt Publishing Company. All rights reserved.

Beller, M. \& Leerssen, J. (2001). Identity, Imagology. A Handbook on the literary representation of national characters, 2001. (Note: the handbook should be published in 2006. Some articles are available at the Handbook's part of the IMAGE website (www.cf.hum.uva.nl/images/dtory.identity.pdf).

Bregoli, I. (2012). Effects of DMO Coordination on Destination Brand Identity: A Mixed-Method Study on the City of Edinburgh. Journal of Travel Research, 52 know what we mean? Journal of Vacation Marketing, 12(4), 299-317.

Bonn, M., Joseph, S. \& Dai, M. (2005). International versus domestic visitors: An Examination of Destination image perceptions. Journal Travel Research, 43(3), 294-301.

Buckley, R. C. (2010). Adventure tourism management. International centre for ecotourism research. Griffith 
University. Gold Coast, Australia.

Buhalis, D. (1999). Marketing the competitive destination for the future: 1999

Buhalis, D. (2000). Marketing the competitive destination of the future. Tourism Management, 21, 97-116.

Cai, L. A. (2002). Cooperative Branding for Rural Destination. Annals of Tourism Research, 29(3), 720-742.

Department of National Park, Wildlife and Plant Conservation from http://www.dnp.go.th

Department of tourism from http://www.tourism.go.th

Flanagan, J. R. \& Lederman, S. (2001). Feeling bumps and holes. Nature, 412, 389- 390.

Framke, W. (2002). The Destination as a Concept: A Discussion of the Business-related Perspective versus the Sociocultural Approach in Tourism Theory. Scandinavian Journal of Hospitality and Tourism, 2(2).

Harris, F. \& Chernatony, L. (2001). Corporate branding and corporate brand performance. European Journal of Marketing, 35(3/4), 441-456.

Keller, K. L. (2003a). Brand synthesis: The multidimensionality of brand knowledge. Journal of Consumer Research, 29(4), 595-600.

Keller, K. L. (2003b). Strategic brand management: Building, measuring, and managing brand equity, 2nd Ed., Prentice Hall, Upper Saddle River, NJ.

Konecnik, M. \& Go, F. (2008). Tourism destination brand identity: the case of Slovenia. Brand Management, 15(3), 177-189.

Kotler, P. (2000). Marketing Management, the Millennium Edition, Prentice Hall.

Mak, A. K. Y. (2011). An identity-centered approach to place branding: Case of industry partners' evaluation of Iowa's destination image.

Morrision, A. \& Anderson, D. (2002). Destination branding Available from: http:// www.macvb.org/intranet/presentation/DestinationBrandingLOzarks6-10-02.

National Economic and Social Development from http://www.nesdb.go.th

Oyserman, D. (2007). Social identity and self regulation. In A. W. Kruglanski \& E. T. Higgins (Eds.), Social psychology: Handbook of basic principles (2nd ed., pp. 432-453). New York: Guilford Press.

Pike, S. (2004). Destination marketing organizations, Elsevier, Amsterdam.

Pike, S. (2005). Tourism destination branding complexity. Journal of Product \& Brand Management, 14(4), 258-9.

Rope, T. \& Mether, J. (2001). Towards the success of the brand: successful marketing image. Helsinki: WSOY.

Rummens, J. (1993). Personal Identity and Social Structure in Sint Maartin/Saint Martin: a Plural Identities Approach. Unpublished Thesis/Dissertation: York University.

Saraniemi, S. (2011). "From destination image building to identity-based branding. International Journal of Culture, Tourism and Hospitality Research, 5(3), 247-254.

Sheehan, L. R. \& Ritchie, J. R. (2005). Brent: Destination Stakeholders, Exploring Identity and Salience. Annals of Tourism Research, 32(3), 711-734.

Starik, M. (1994). The Toronto conference: Reflections on stakeholder theory. Business and Society, 33(1), 8995.

Schiffman, G. \& Kanuk, L. (2000). Consumer Behavior\|, Prentice-Hall International, 2000.

Tybout, A. M. \& Stephen, B. (2005). Kellogg on branding. New York: John Wiley \& Sons Inc.

Upshaw, L. B. (1995). Building brand identity: A strategy for success in a hostile marketplace. New York: Wiley.

Weinreich, P. \& Saunderson, W. (2003). Analyzing Identity: Cross-Cultural, Societal and Clinical Contexts. London: Routledge. http:// www.Traveling. Webarchive (15.03.2016) 